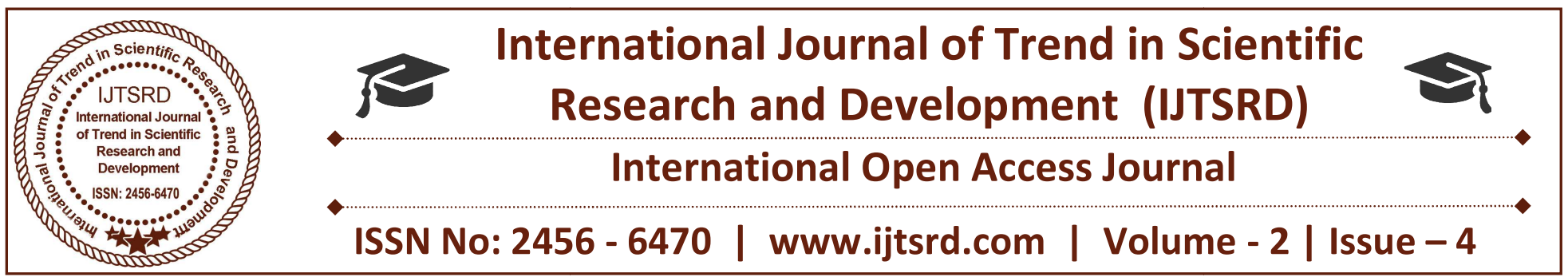

\title{
To diminish the rates of medication errors and increase patient compliance: Using health information technology as tool
}

\author{
Dr. Devesh Kapoor* \\ Dr. Dayaram Patel Pharmacy \\ College, Bardoli, Surat, Gujarat
}

\author{
Mrs. Ruchi B Vyas \\ Dr. Dayaram Patel Pharmacy \\ College, Bardoli, Surat, Gujarat
}

\author{
Mr. Diwakar Dadarwal \\ Sanjeevni College of \\ Pharmaceutical Sciences \\ Rajota, Khteri, Rajasthan
}

\section{ABSTRACT}

Medication errors have been increasingly recognized as a major cause of iatrogenic illness and system-wide improvements have been the focus of prevention efforts. Critically ill patients are particularly vulnerable to injury resulting from medication errors because of the severity of illness, need for high risk medications with a narrow therapeutic index and frequent use of intravenous infusions. According to healthcare and health industry leaders, using information technology enhances patient safety by preventing medical errors, assessment errors and surveillance system with rapid response and reduces the risk of harm created after the fact. Health information technology has been identified as a method to reduce medication errors as well as improve the efficiency and quality of care; however, few studies regarding the impact of health information technology have focused on patients in the intensive care unit. Computerized physician order entry and clinical decision support systems can play a crucial role in decreasing errors in the ordering stage of the medication use process through improving the completeness and legibility of orders, alerting physicians to medication allergies and drug interactions and providing a means for standardization of practice. Electronic surveillance, reminders and alerts identify patients susceptible to an adverse event, communicate critical changes in a patient's condition, and facilitate timely and appropriate treatment. In this paper, medical errors are investigated, the role of information technology in reducing and preventing medical errors is investigated, and recommendations are presented regarding the use of information technology for prevention and reduction of medical errors in healthcare institutions. Scientific databases and electronic journal citations were searched to identify articles that discussed the role of health information technology in reducing preventable medical errors and improving patient safety.

Keywords: Intensive care unit, Clinical decision support system, Bar coded medication, Wireless sensor network, Electronic health record

\section{INTRODUCTION}

Prevention of medication errors has therefore become a high priority worldwide. There is mounting evidence that systems that use information technology (IT), such as computerized physician order entry, automated dispensing cabinets, bedside bar-coded medication administration, and electronic medication reconciliation, are key components of strategies to prevent medication errors. [1,2] Adverse drug events (ADEs) represent an unwanted complication of hospital care and medication errors have been increasingly recognized as a major cause of iatrogenic injury. While their frequency, severity, cost, and optimal prevention strategies remain a source of debate, a single event is capable of generating enormous negative publicity, compromising patient trust, and demoralizing hospital staff. [3,4]. Medical errors are an increasing public concern among policy-makers, healthcare providers and experts. Improving patient safety involves analyzing and 
learning from adverse events and developing or adapting systems to reduce reliance on individual vigilance. Taking advantage of advances in computers and networking can aid clinical decision support and provide better information flow within and between systems. Strategic equipment design can prevent or mitigate harm to patients. Technology in health care, along with organizational culture change, promises to be an extremely effective safeguard against human fallibility. Improving the performance of skilled medical professionals is unlikely to be achieved by exhorting them to work better, faster, or more cheaply. They are already making decisions, planning their time, remembering key information, and preventing adverse events as well as the limits of human ability will allow. Further advances will require some form of assistance. Investing in technology to improve safety, as the automotive, aviation, and nuclear industries have done, is the next logical step. It will be critical to have information technology infrastructure in health care that not only supports the standardized identification, reporting, and tracking of patient data, but that also reduces and, where plausible, prevents errors. Medical errors are repeated constantly, as in life occur. Most medical errors have less likely to cause damage, but some of them can lead to irreparable damage. Medical errors are an inevitable part of the results of human performance. Errors investigation as a source of information about the health of an organization can be a good experience to improve patient safety. [5]

\section{The medication management process of medication:}

Medication management is a complex, multifaceted operation involving multiple people and numerous steps. Table 1 describes the various steps in a typical medical management process, the estimated error rate for each step, and the 'true' error rate based on the likelihood that the error will be intercepted
Table 1 Diverse IT systems in medication error management

\begin{tabular}{|l|l|l|l|l|}
\hline Stage & $\begin{array}{l}\text { Erro } \\
\mathbf{r} \\
\text { rate } \\
\%\end{array}$ & $\begin{array}{l}\text { Interce } \\
\mathbf{p t} \\
\text { rate \% }\end{array}$ & $\begin{array}{l}\text { Tru } \\
\text { e } \\
\text { erro } \\
\mathbf{r} \\
\text { rate } \\
\text { \% }\end{array}$ & $\begin{array}{l}\text { Relevant } \\
\text { IT systems }\end{array}$ \\
\hline Prescription & 40 & 49 & 24 & $\begin{array}{l}\text { CPOE with } \\
\text { decision } \\
\text { support }\end{array}$ \\
\hline $\begin{array}{l}\text { Transcriptio } \\
\text { n }\end{array}$ & 11 & 35 & 12 & $\begin{array}{l}\text { Automated } \\
\text { transcriptio } \\
\text { n }\end{array}$ \\
\hline Dispensing & 12 & 32 & 11 & $\begin{array}{l}\text { Robots, } \\
\text { automated } \\
\text { dispensing } \\
\text { cabinets }\end{array}$ \\
\hline $\begin{array}{l}\text { administrati } \\
\text { on }\end{array}$ & 41 & 3 & 52 & $\begin{array}{l}\text { Bar coding, } \\
\text { electronic } \\
\text { medication } \\
\text { administrati } \\
\text { on }\end{array}$ \\
\hline
\end{tabular}

\section{Classification of tools of information technology to} thwart errors related to medication:

1. Clinical decision support system

2. Computerized physician order entry system (CPOE)

3. Bar coded medication

4. Wireless sensor network

5. Electronic health record (EHR)

6. Bar coded pharmacy dispensing system

7. Radio frequency identification (RFID)

\section{Clinical decision support system}

CDSS provides clinical knowledge and information related to the patient to clinicians. CDSS selects them intelligently and displays it at the proper time. The information integrates the computerized patient records with the complete data repository accurately. Improving the healthcare organization's performance through computer based clinical decision support systems, is the common use of information technology in the health area. Baseline data with handwritten orders was compared to:

1. CPOE with minimal CDSS,

2. CDSS with drug allergy checking 
International Journal of Trend in Scientific Research and Development (IJTSRD) ISSN: 2456-6470

3. CDSS with additional drug-drug interaction screening and pathways for potassium prescribing and administration.

CDSS improves medication dosing accuracy in patients with renal dysfunction. Prescribing of the correct dose and frequency increased significantly with the addition of guided medication dosing, from $54 \%$ to $67 \%$ and $35 \%$ to $59 \%$, respectively. There was a significant reduction in the mean length of stay, 0.3 days, in patients with guided dosing. [6, 7]

\section{Computerized physician order entry system (CPOE)}

Computerized physician order entry (CPOE) is an application in which physicians write orders online. This system has probably had the largest impact of any automated intervention in reducing medication errors; the rate of serious errors fell $55 \%$ in one study and the rate of all errors fell $83 \%$ in another. $[8,9]$

\section{CPOE systems work by}

making sure that the order is legible and complete, including all necessary information, such as dose, route, and dosage form

$>$ checking for problems such as drug allergies and drug-drug interactions

$>$ providing dosage adjustment calculations based on clinical features such as weight or renal function

> checking for appropriate baseline laboratory results such as platelet count and international normalized ratio for patients receiving anticoagulants

$>$ computing drug- laboratory interactions, such as alerting the prescriber to a low potassium concentration when digoxin is being prescribed

$>$ Updating the prescriber with the latest drug information, such as the need to avoid rofecoxib after it had been withdrawn by the manufacturer.

\section{Bar coded medication}

Although few data from health care are available, bar coding of drugs also seems useful for reducing error rates. The major barrier to implementation has been that drug manufacturers have not been able to agree on a common approach; this should be legislated. Bar coding is widely used in many industries outside medicine; it results in error rates about a sixth of those due to keyboard entry and is less stressful to workers. Bar code technology is a method to reduce medication errors that other systems, such as CPOE, cannot detect and intercept. In 2004, the Food and Drug Administration (FDA) required that all newly approved drugs be packaged with a linear bar code, containing the National Drug Code number, within 60 days of approval. Despite the FDA mandate, the implementation of bar coding technology within healthcare systems has been slow. Inpatient hospital pharmacy operations are complex, requiring multiple steps, involving vital interactions of personnel and technology. [10]

\section{Wireless sensor network $[11,12]$}

Healthcare is always an important and critical concern as it is a matter of human livings. It has always a great importance in each aspect of field. There is a huge application area of WSN in healthcare sector. In this work we have tried to summarize the all applications area of WSN. We have categorized the applications of WSN in healthcare sector in different categories.

These types of applications are widely used to monitor the status of patient either in hospital or home. They intimate the doctors if there is a critical situation with a patient. They monitor the heart rate, oxygen rate, blood pressure, body temperature and other information about a patient

MobiHealth is a mobile healthcare application which allows the patient to be mobile every time and they are being monitored continuously by using GRPS network. Vital Jacket is also a smart mobile device, which is used as a wearable jacket used to monitor the heartbeat of the patient. It continuously measures the heart rate after a regular interval and updates the report of the patient to its consultant. It has alarming sensors which in case of emergency rapidly informs.

AlarmNet is also a mobile device, consisting of different wireless sensor networks. They sense the heart rate and oxygen rate, and alarm in case of any emergency.

LifeGuard was first developed for the astronauts. The basic purpose of this application is to monitor the blood pressure and pulse beat.

CodeBlue was a large scale project, and it provides a framework in providing rapid response against the disaster situations. It allows the quick remote monitoring and tracing the patient's situation. LifeShirt is also a wearable shirt device, and is 
available commercially. It consists of different sensors and data recorders. It is a complete package including recording software which update regularly the patient status like its blood pressure, heart beat rate and pulse rate etc.

SleepApnea is very useful mobile device which is used to monitor the different parameters of the patient in night while he is sleeping, it monitors the blood circulation, the oxygen intake, breathing and the heart rate etc. it provides a rapid response in case of any casualty.

\section{Electronic health record (EHR)}

Electronic health records (EHRs) have been widely adopted over the past decade in both inpatient and outpatient settings. EHR systems are made up of the electronic patient "chart" and typically include functionality for computerized provider order entry (CPOE), laboratory and imaging reporting, and medical device interfaces. Ideally, the system creates a seamless, legible, comprehensive, and enduring record of a patient's medical history and treatment. However, the transition to this new way of recording and communicating medical information has also introduced new opportunities for error and other unanticipated consequences that can present safety risks. An individual can maintain a paper-based record, but in the current context a PHR is defined as 'a set of computer-based tools that allow people to access and coordinate their lifelong health information and make appropriate parts of it available to those who need it. Implementation of such a record may consist of a 'stand-alone' website for patients to enter their medical data, or a physician/hospital-hosted patient portal, giving patients access to their electronic health record (EHR), or an employer/payer portal giving patients access to claims data. EHR collects health information throughout a person's lifetime electronically. The information is transmitted and maintained securely. In fact, EHR includes all of the information related to the health of a person's life such as experiments, interpretations, plans, procedures, allergies, diseases and injuries, evaluations, immunization data, behavioral, environmental, demographic, legal and administrative data. $[13,14]$

\section{Bar coded pharmacy dispensing system:}

Barcoded Medication Administration (BCMA) is an inventory control system that uses barcodes to prevent human errors in the distribution of prescription medications at hospitals. The goal of BCMA is to make sure that patients are receiving the correct medications at the correct time by electronically validating and documenting medications. The information encoded in barcodes allows for the comparison of the medication being administered with what was ordered for the patient. A BCMA system consists of a barcode printer, a barcode reader, a mobile computer (with Wi-Fi), a computer server and software. Each drug in the hospital is labeled with a unique barcode. When a patient is prescribed medication, it is faxed, sent electronically or hand delivered to the hospital's pharmacy and entered into a computer system by a pharmacist. The pharmacist dispenses the barcoded dose of the drug to the patient's floor. When it's time for the clinician to administer the medication, he uses a handheld device to scan the barcodes on his identification badge, the patient's wristband and the drug. If the barcode pointof-care (BPOC) system cannot match the drug to be given with the order in the system, it alerts the clinician with a visual warning. Each patient's barcode holds all the vital information about the patient and his medication. [15]

The Five Rights of Barcode Medication

Administration:

a.The right patient

b. The right medication

c. At the right time

d. At the right dose

e. By the right route

\section{Radio frequency identification (RFID):}

RFID (Radio Frequency Identification) can be defined as follows: Automatic identification technology which uses radio-frequency electromagnetic fields to identify objects carrying tags when they come close to a reader. RFID tags generally feature an electronic chip with an antenna in order to pass information onto the interrogator (also known as a base station or more generally, reader). The assembly is called an inlay and is then packaged to be able to withstand the conditions in which it will operate. This finished product is known as a tag, label or transponder. RFID is an area of automatic identification that is gaining momentum and is considered by some to emerge as one of the most pervasive computing technologies in history. In its simplest form, RFID is a similar 
concept to bar coding. It is seen as a means of enhancing data processes and is complementary to existing technologies. It is a proven technology that has been in use since the 1970s. The principal advantages of RFID system are the non-contact, nonline-of-sight characteristics of the technology. Tags can be read through a variety of visually and environmentally challenging conditions such as snow, ice, fog, paint, grime, inside containers and vehicles and while in storage. Medical errors could be prevented by building a safer healthcare system. Recently, the RFID has been applied in hospital management. The RFID is valuable for quickly retrieving patient information and monitoring patient locations in the hospital. Chao et al, in a study titled improving patient safety with RFID and mobile technology announced "These medical errors can be classified into five categories: poor decision making, poor communication, inadequate patient monitoring, patient misidentification, inability to respond rapidly and poor patient tracking. Employing innovative information technologies in correcting these deficiencies and meeting the Joint Commission on Accreditation of Healthcare Organization (JCAHO) patient safety goals is the current trend in enhancing patient safety"

\section{Conclusion:}

Information technology improves healthcare system, regardless of the type of technology used, by one of the followings: documentation (test results, clinical reports, recommendations and consultation), and providing communication between the patient and each other providers, facilitating data entry, identification and evaluation of risks. The implementation of health information technology can result in a reduction in ADEs and can impact the quality of patient care. Systems integration and compliance are vital in achieving a safe medication use process. Hospitals that have extensive computerized technology and have greater automation tend to have better patient outcomes, including fewer complications, reduced inpatient mortality and lower hospital costs. In the healthcare industry, there are other advantages for example; increase accuracy tasks, reduce human errors, improve safety, and patient satisfaction. No doubt, in coming years, using of the RFID will be a requirement in the healthcare industry. Although, the sole usage of RFID will not be able meet expectation of health care organizations. If it is used alone, health care organizations will be faced with numerous challenges. But, if we integrate it with hospital information systems (HIS) and electronic health records (EHRs) and support it by clinical decision support systems (CDSS), it facilitates magically processes and reduces medical, medication and diagnosis errors. IT systems are key components of a multifaceted strategy to prevent medication errors and improve patient safety. However, we need to be mindful of their potential to affect clinical workflow adversely, with attendant complications. Improving standardization and certification of the design and implementation of such systems should help. In addition, creating an economic and policy environment conducive to the financial goals of hospitals and physicians will facilitate wider adoption.

\section{References:}

1) Mongan JJ, Ferris TG, Lee $T H$. Options for slowing the growth of health care costs. N Engl J Med 2008; 358: 1509-1514.

2) Hillestad R, Bigelow J, Bower A, Girosi F, Meili R, Scoville R, Taylor R. Can electronic medical record systems transform health care? Potential health benefits, savings, and costs. Health Aff (Millwood) 2005; 24: 1103-1117.

3) Bates DW, Cullen DJ, Laird N, et al. Incidence of adverse drug events and potential adverse drug events. JAMA 1995; 274: 29-34.

4) Chyka PA. How many deaths occur annually from adverse drug reactions in the United States? Am J Med 2000; 122-130.

5) Bates DW, Spell N, Cullen DJ. The cost of adverse drug events in hospitalized patients. JAMA 1997: 277: 307-311.

6) Classen DC. Clinical decision support systems to improve clinical practice and quality of care. JAMA 1998; 280:1360-1361.

7) Weant K, Cook AM, Armitstead JA. Medicationerror reporting and pharmacy resident experience during implementation of computerized prescriber order entry. Am J Health-Syst Pharm 2007; 64: 526-530.

8) Bates DW, Leape LL, Cullen DJ, Laird N, Petersen LA, Teich JM, et al. Effect of computerized physician order entry and a team intervention on prevention of serious medication errors. JAMA 1998; 280:1311-6.

9) Bates DW, Teich J, Lee J, Seger D,Kuperman GJ, Boyle D, et al. The impact of computerized physician order entry on medication error 
International Journal of Trend in Scientific Research and Development (IJTSRD) ISSN: 2456-6470

prevention. $J$ Am Med Informatics Assoc 1999;6:313-21.

10) Chester MI, Zilz DA. Effects of bar coding on a pharmacy stock replenishment system. Am J Hosp Pharm 1989; 46:1380-5.

11) T. Arampatzis, J. Lygeros, and S. Manesis, "A survey of applications of wireless sensors and wireless sensor networks," in Intelligent Control, 2005. Proceedings of the 2005 IEEE International Symposium on, Mediterrean Conference on Control and Automation, 2005, pp. 719-724.

12) A. Milenković, C. Otto, and E. Jovanov, "Wireless sensor networks for personal health monitoring: Issues and an implementation," Computer communications, vol. 29, pp. 2521-2533, 2006.

13) Markle Foundation. Connecting for Health. A Public-Private Collaborative. Final Report. 1 July 2003. http://www.connectingforhealth.org/resources/fina 1_phwg_report1.pdf(last accessed 10 April 2018).

14) Ehteshami A, Sadoughi F, Saeedbakhsh S, Isfahani MK. Assessment of medical records module of health information system according To ISO 9241-10. Acta Inform Med 2013; 21:36-41.

15) Chester MI, Zilz DA. Effects of bar coding on a pharmacy stock replenishment system. Am J Hosp Pharm 1989;46:1380-5.

16) Lai CL, Chien SW, Chang LH, Chen SC, Fang K. New York: IEEE Institute of Electrical and Electronics Engineers; 2007. Enhancing medication safety and healthcare for inpatients using RFID.

17) Chao CC, Jen WY, Chi YP, Lin B. Improving patient safety with RFID and mobile technology. Int J Electron Health. 2007;3:175-92.

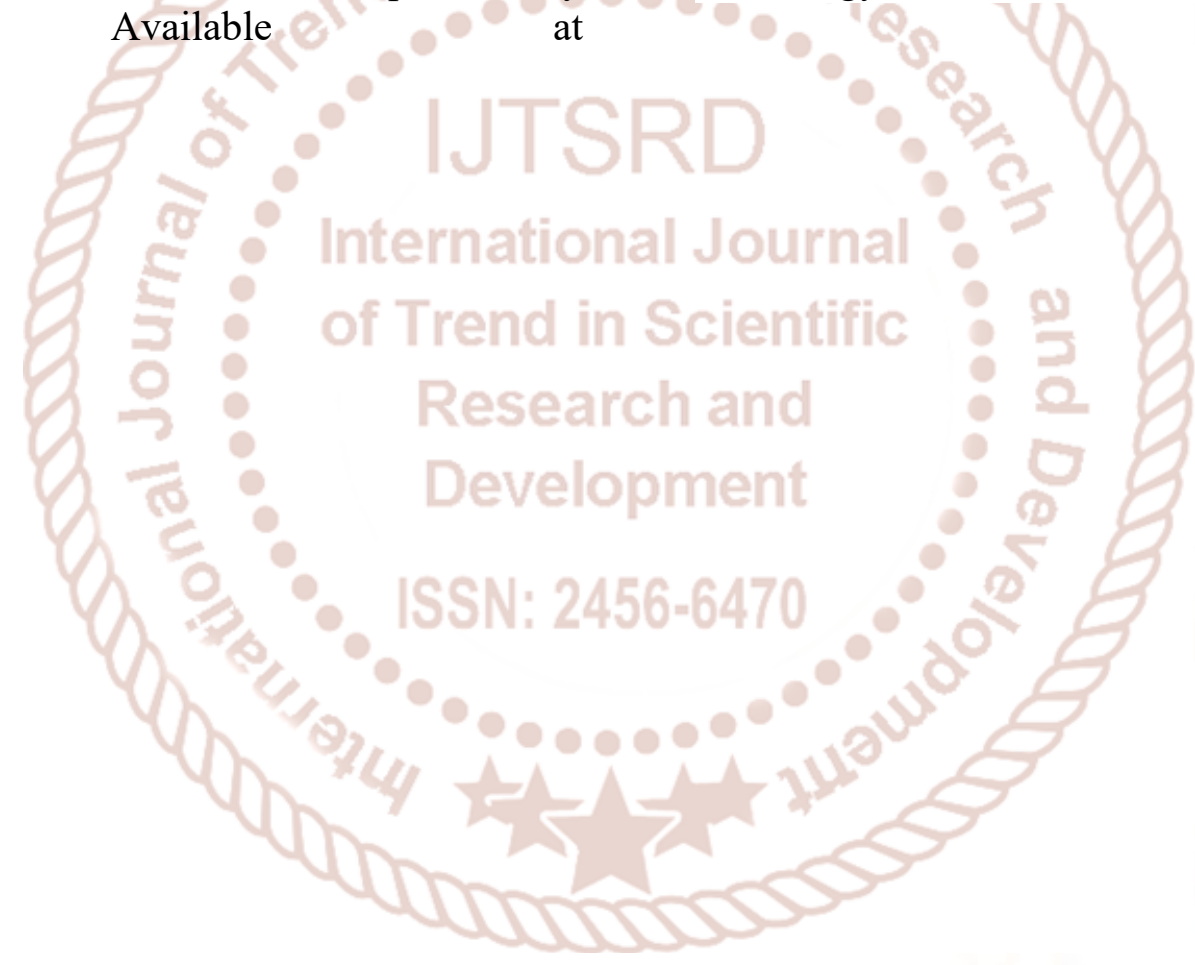

